\title{
Evaluation of the Automated System Vitek2 for Identification and Antimicrobial Susceptibility Testing of Brazilian Gram-Positive Cocci Strains
}

\author{
Pedro Alves d’Azevedo ${ }^{1}$, Itacy Siquiera ${ }^{2}$, Juliana Gugel ${ }^{2}$, Ana Lúcia Souza Antunes ${ }^{1}$, Carina Secchi ${ }^{1}$, Jacyr Pasternak ${ }^{2}$ and \\ Marinês Dalla Vale Martino ${ }^{2}$ \\ ${ }^{1}$ Department of Microbiology and Parasitology of the Foundation of Clinical Medical School of Porto Alegre (FFFCMPA), Porto Alegre,RS; \\ ${ }^{2}$ Clinical Laboratory of Hospital Israelita Albert Einstein; São Paulo, SP, Brazil
}

\begin{abstract}
Automated instruments offer many advantages for clinical laboratories. Nevertheless, they can have problems identifying and determining susceptibilities of some pathogens. Vitek ${ }^{\circledR} 2$ (bioMérieux) is an automated system that was recently introduced to Brazil. We evaluated the performance of this equipment for Brazilian isolates that had been characterized using reference identification and antimicrobial susceptibility testing methods. Ninety-nine strains of Gram-positive cocci from a local reference center collection were analyzed, consisting of 50 coagulase-

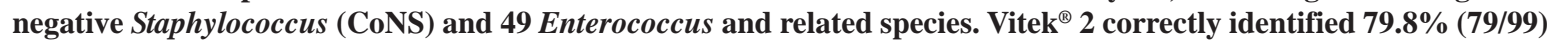
of the isolates. Oxacillin resistance was detected in $76 \%(19 / 25)$ of resistant $S$. epidermidis strains and in $88 \%(22 / 25)$ of other resistant CoNS species strains. Vancomycin resistance was detected in 100\% (20/20) of resistant Enterococcus and related species strains. Vitek ${ }^{\circledR} 2$ performed very well for the identification of $S$. epidermidis and non-epidermidis staphylococci, and for the detection of vancomycin resistance in Enterococcus and related species. However, the system needs improvement in order to provide reliable results for the characterization of some CoNS species, identification of Enterococcus and related species and for detecting oxacillin resistance in CoNS.

Key-Words: Automated system, Vitek2, Gram-positive cocci, identification, antimicrobial susceptibility testing.
\end{abstract}

Automated instruments offer many advantages in clinical laboratories, especially in hospitals. Such instruments improve workflow and provide faster results than conventional methods. Nevertheless, they can have problems identifying and determining susceptibilities of some pathogens. Coagulase-negative staphylococci (CoNS) are the most common microorganisms isolated from blood cultures; however, $85 \%$ of the isolates are contaminants, usually from skin contamination at the time of collection [1]. Nevertheless, CoNS are recognized as important nosocomial pathogens; in many institutions, they are among the main agents of nosocomial bacteremias [2-4]. Many clinical laboratories do not routinely identify CoNS to the species level when these microorganisms are detected in blood or other body fluids. However, the significance of CoNS as pathogens has increased. Blood culture isolates should therefore be identified to the species level to determine their clinical relevance and monitor their epidemiology [5]. Resistance to methicillin among these microorganisms is a matter of concern, because of the increasingly high levels that have been detected. In a multicenter study in Brazil, methicillin resistance was observed in $87.7 \%$ of CoNS isolated from bloodstream infections [6]. Accurate detection of methicillin resistance among CoNS isolates in the clinical laboratory is important to guide therapy and to promote the correct use of glycopeptides [3,7].

Received on 10 May 2008; revised 12 December 2008.

Address for correspondence: Dr. Pedro A. d'Azevedo. Universidade Federal de Ciências da Saúde de Porto Alegre. Rua Sarmento Leite 245/ 204, Porto Alegre, RS. Zip code: 90050-170, Brazil. Phone: 5551 33038740. Fax: 5551 32269756. E-mail: pedroaze@ufcspa.edu.br. This study was presented in part at the $107^{\text {th }}$ General Meeting of the American Society for Microbiology, Toronto, Canada, 2007. Financial support: CNPq, FFFCMPA.

The Brazilian Journal of Infectious Diseases 2009;13(2):107-110. (C) 2009 by The Brazilian Journal of Infectious Diseases and Contexto Publishing. All rights reserved.
The importance of the enterococci as nosocomial pathogens has been widely documented in recent years; vancomycinresistant enterococci (VRE) are particularly relevant due to their increasing prevalence and their capability to acquire antimicrobial resistance. Enterococcus faecalis is the species most frequently associated with human infections, followed by Enterococcus faecium [8].

In general, these two species are responsible for about 90 to $95 \%$ of enterococcal infections in humans. The remaining 5 to $10 \%$ are caused by other members of the genus.

Automated systems, such as Vitek ${ }^{\circledR}$ legacy (bioMérieux) and MicroScan ${ }^{\circledR}$ (DadeBehring), are also frequently used for rapid identification and antimicrobial susceptibility testing of Gram-positive cocci in clinical laboratories around the world [9-13]. Vitek ${ }^{\circledR} 2$ (bioMérieux) is an automated system recently introduced to Brazil. We evaluated the performance of this system with Brazilian isolates that had been characterized using reference methods of identification (ID) and antimicrobial susceptibility testing (AST).

\section{Material and Methods}

Isolates

Ninety-nine isolates of Gram-positive cocci from a local reference center collection were analyzed: 50 Coagulasenegative Staphylococcus (CoNS) and 49 Enterococcus spp. and related species. They were obtained from a culture collection maintained in the Microbiology department, Universidade Federal de Ciências da Saúde de Porto Alegre. The isolates were kept at $-20^{\circ} \mathrm{C}$ in skim milk (Difco) plus $20 \%$ glycerol.

Quality control of the tests was done using Enterococcus faecalis ATCC 29212, Enterococcus faecium SS 1274, Staphylococcus epidermidis ATCC 12228, Staphylococcus saprophyticcus CCM 883, Staphylococcus hominis ATCC 27844 and Staphylococcus haemolyticcus CCM 2737. 
The isolates were identified by conventional biochemical tests $[8,14]$.

Most isolates were also identified by analysis of electrophoretic whole-cell protein profiles according to the procedures described by Merquior et al. [15] for enterococci and by molecular (sodA sequencing) methods for CoNS [16]. Conventional antimicrobial susceptibility testing Susceptibilities to oxacillin and vancomycin were detected by the disk-diffusion (DD), Etest ${ }^{\circledR}$ (AB Biodisk, Solna, Suécia) and agar dilution (CLSI) [17] procedures. The mecA and vanA alleles were detected by PCR; this was considered the "gold standard" method [18,19].

Identification and Antimicrobial Susceptibility Testing Using Automated Systems

Species identification and antimicrobial susceptibility were determined using the automated systems Vitek $2{ }^{\circledR}$ (bioMérieux - software 4,03), panel GP card (identification) and GP01 (susceptibility testing). The manufacturer's instructions were followed for the preparation of the inoculua and incubation of the isolates.

\section{Results}

Based on the combination of results obtained from the conventional biochemical tests, the 99 isolates of CoNS, enterococci and related genera were identified as follows: CoNS - 25 S. epidermidis, 3 S. haemolyticus, 3 S. sciuri, 2 S. warneri, 2 S. cohnii subsp. cohnii, 2 S. capitis subsp. capitis, 2 S. hominis subsp. hominis, 2 S. hominis subsp. novobiosepticus, 2 S. cohnii subsp. urealyticus, 1 S. caprae, 1 S. auricularis, 1 S. equorum, 1 S. lugdunensis, 1 S. saprophyticus, 1 S. simulans and 1 S. xilosus. Enterococci and related genera - $17 \mathrm{E}$. faecium, $9 \mathrm{E}$. faecalis, $7 \mathrm{E}$. gallinarum, 3 E. avium, 2 E. casseliflavus, 2 E. hirae, 1 E. durans, 1 E. raffinosus, 1 Lactococcus garvieae, 2 Leuconostoc pseudomesenteroides, 2 Streptococcus bovis and 2 Pediococcus sp.

Vitek2 correctly identified 80 of the 99 isolates (accuracy of $80.8 \%$ ), 43/50 (86\%) of CoNS and 37/49 (75.5\%) of Enterococcus sp. and related species. Among CoNS, the identifications were concordant for S. epidermidis, $S$. caprae, S. capitis subsp. capitis, S. cohnii subsp. urealyticus, S. lugdunensis, S. haemolyticus, S. hominis subsp. hominis, S. sciuri, and $S$. warneri. The system failed to identify the other species and subspecies tested. Among Enterococcus sp. and related species the identifications were as follows: Enterococcus sp. 71.4\% (30/42), Pediococcus sp. $0 \% \quad(0 / 2), \quad$ Leuconostoc pseudomesenteroides 100\% (2/2), Lactococcus garviae $100 \%(1 / 1)$, and Streptococcus bovis 0\% (0/2) (Table 1). Methicillin resistance was associated with the mecA gene in 19 of the 25 samples (76.0\%) in S. epidermidis isolates and in 22/25 (88\%) in other CoNS species. Vancomycin resistance was detected in $100 \%$ of the Enterococcus species and related genera (20/20) (Tables 1 and 2).

\section{Discussion}

Automated methods are faster and improve laboratory workflow. Most of the discrepant results in identification involved the less-frequently-isolated species. We need to be cautious when CoNS other than $S$. epidermidis are identified with this system. Nonhoff et al. (2005) [20] found similar limitations when he tested Vitek ${ }^{\circledR} 2$ on methicillin-resistant staphylococci from Belgium. We must also be cautious with the less frequent Enterococcus sp. and related species. Vitek ${ }^{\circledR} 2$ performed well and identified these two species; it correctly identified 25/26 (96.2\%) of E. faecalis and E. faecium, which are normally responsible for approximately $90 \%$ to $95 \%$ of enterococcal infections in humans.

For less-frequently-isolated species, Vitek ${ }^{\circledR} 2$ may need improvement. A major mistake was made with E. gallinarum, an important vancomycin-resistant pathogen, which should be correctly identified in a clinical hospital laboratory.

The system had good performance in the determination of methicillin resistance, especially for $S$. non-epidermidis $22 / 25$ (88\%). However, the interpretative criteria of the CLSI (2005) may overestimate resistance of the other species. The discrepancies in the susceptibility tests for CoNS included major errors. The Minimum Inhibitory Concentration (MICs) determination of the strains that showed false resistance were near the established breakpoints to classify them as susceptible. According to the CLSI (2008) [17], strains isolated from serious infections that have MICs varying from 0.5 to 2.0 $\mu \mathrm{L} / \mathrm{mL}$ should be tested for the presence of the mecA gene or for the protein expressed by this gene, considering that they may present confusing phenotypes. Less frequent species of CoNS have been associated with serious infections in hospital institutions, and these have become increasingly common.

The advantages of automated systems for species identification and antimicrobial susceptibility testing are speed and better workflow. Improvements in their accuracy would help make them practical.

In the analysis of vancomycin resistance in Enterococcus sp. and related species the automated system detected 20/20 isolates $(100 \%)$. Considering that vancomycin-resistant enterococci require implementation of infection control measures, some species identification is needed.

The reporting time for CoNS identification by the VITEK 2 system ranged from $4.25 \mathrm{~h}$ to $8 \mathrm{~h}$, and the mean time to result was 5.79h. Enterococci required from 3.25 h to 8 h to identify; the mean time was $5.78 \mathrm{~h}$.

In conclusion, the automated system Vitek2 needs further improvement in order to provide reliable results for the characterization of the other CoNS and enterococci-related species and for detection of oxacillin resistance.

\section{Acknowledgements}

The authors thank bioMérieux, the Microbiology group of the Hospital Israelita Albert Einstein, and the Conselho Nacional de Desenvolvimento Científico e Tecnológico (CNPq) for financial technical support. 
Table 1. Comparison of identification of isolates by the Vitek2 automated system with identifications using conventional identification methodology.

\begin{tabular}{|c|c|}
\hline Conventional identification & Vitek2 identification \\
\hline Staphylococcus epidermidis $(\mathrm{n}=25)$ & S. epidermidis $(\mathrm{n}=25)$ \\
\hline S. haemolyticus $(\mathrm{n}=3)$ & S. haemolyticus $(\mathrm{n}=3)$ \\
\hline S. sciuri $(\mathrm{n}=3)$ & S. sciuri $(\mathrm{n}=3)$ \\
\hline S. warneri $(\mathrm{n}=2)$ & S. warneri $(\mathrm{n}=2)$ \\
\hline S. cohnii subsp cohnii $(\mathrm{n}=2)$ & S. cohnii subsp urealyticus $(\mathrm{n}=2)$ \\
\hline S. capitis subsp capitis $(\mathrm{n}=2)$ & S. capitis subsp capitis $(\mathrm{n}=2)$ \\
\hline S. hominis subsp hominis $(\mathrm{n}=2)$ & S. hominis subsp hominis $(\mathrm{n}=2)$ \\
\hline S. hominis subsp novobiosepticus $(\mathrm{n}=2)$ & S. hominis $(\mathrm{n}=2)$ \\
\hline S. cohnii subsp urealyticus $(\mathrm{n}=2)$ & S. cohnii subsp urealyticus $(\mathrm{n}=2)$ \\
\hline S. auricularis $(\mathrm{n}=1)$ & S. warneri $(\mathrm{n}=1)$ \\
\hline S. caprae $(\mathrm{n}=1)$ & S. caprae $(\mathrm{n}=1)$ \\
\hline S. equorum $(\mathrm{n}=1)$ & S. xilosus $(\mathrm{n}=1)$ \\
\hline S. lugdunensis $(\mathrm{n}=1)$ & S. lugdunensis $(\mathrm{n}=1)$ \\
\hline S. saprophyticus $(\mathrm{n}=1)$ & S. warneri $(\mathrm{n}=1)$ \\
\hline S. simulans $(\mathrm{n}=1)$ & S. haemolyticus $(\mathrm{n}=1)$ \\
\hline S. xilosus $(\mathrm{n}=1)$ & S. hominis $(\mathrm{n}=1)$ \\
\hline \multirow[t]{2}{*}{ Enterococcus faecium $(\mathrm{n}=17)$} & E. faecium $(\mathrm{n}=16)$ \\
\hline & E. gallinarum $(\mathrm{n}=1)$ \\
\hline E. faecalis $(\mathrm{n}=9)$ & E. faecalis $(\mathrm{n}=9)$ \\
\hline \multirow[t]{4}{*}{ E. gallinarum $(\mathrm{n}=7)$} & E. gallinarum $(\mathrm{n}=3)$ \\
\hline & E. casseliflavus $(\mathrm{n}=1)$ \\
\hline & E. durans $(\mathrm{n}=1)$ \\
\hline & E. faecalis $(\mathrm{n}=2)$ \\
\hline \multirow[t]{2}{*}{ E. $\operatorname{avium}(\mathrm{n}=3)$} & E. $\operatorname{avium}(\mathrm{n}=2)$ \\
\hline & E. faecium $(\mathrm{n}=1)$ \\
\hline E. casseliflavus $(\mathrm{n}=2)$ & E. casseliflavus $(\mathrm{n}=1)$ \\
\hline \multirow[t]{2}{*}{ E. hirae $(\mathrm{n}=2)$} & E. hirae $(\mathrm{n}=1)$ \\
\hline & E. durans $(\mathrm{n}=1)$ \\
\hline E. durans $(\mathrm{n}=1)$ & E. hirae $(\mathrm{n}=1)$ \\
\hline Lactococcus garvieae $(\mathrm{n}=1)$ & Lactococcus garvieae $(\mathrm{n}=1)$ \\
\hline Leuconostoc pseudomesenteroides $(\mathrm{n}=2)$ & Leuconostoc pseudomesenteroides $(\mathrm{n}=2)$ \\
\hline \multirow{2}{*}{ Streptococcus bovis $(\mathrm{n}=2)$} & Lactococcus garvieae $(\mathrm{n}=1)$ \\
\hline & Pediococcus $(n=1)$ \\
\hline Pediococcus (n=2) & E. faecalis $(\mathrm{n}=2)$ \\
\hline Total & 99 \\
\hline
\end{tabular}

Table 2. Discrepancies in the susceptibility tests and type of error in identifying coagulase-negative Staphylococcus based on PCR identification of the mecA gene compared with the automatic testing system Vitek2.

\begin{tabular}{llcc}
\hline Isolates & mecA & $\begin{array}{c}\text { Vitek2 } \\
\text { Phenotype }\end{array}$ & Error \\
\hline S. epidermidis $(\mathrm{n}=1)$ & Pos. & $\mathrm{S}$ & $\mathrm{VM}$ \\
S. epidermidis $(\mathrm{n}=5)$ & Neg. & $\mathrm{R}$ & $\mathrm{M}$ \\
S. cohnii subsp. urealyticus $(\mathrm{n}=1)$ & Pos. & $\mathrm{S}$ & VM \\
S. warneri $(\mathrm{n}=1)$ & Pos. & $\mathrm{S}$ & $\mathrm{VM}$ \\
S. capitis $(\mathrm{n}=1)$ & Neg. & $\mathrm{R}$ & $\mathrm{M}$ \\
\hline
\end{tabular}

\section{References}

1. Weinstein M.P., Towns M.L., Quartey S.M., et al. The clinical significance of positive blood culture in the 1990s: a prospective comprehensive evaluation of the microbiology, epidemiology and outcome of bacteremia and fungemia in adults. Clin Infect Dis 1997;24:584-602.
2. Cockerill F.R., III J.G., Hughes E.A., Vetter E.A., et al. Analysis of 281797 consecutive blood cultures performed over an eight-year period: trends in microorganisms isolated and the value of anaerobic culture of blood. Clin Infect Dis 1997;24:403-18. 
3. Hussain Z., Stoakes L., Lannigan R., et al. Evaluation of Screening and Commercial Methods for Detection of Methicillin Resistance in Coagulase-Negative Staphylococci. J Clin Microbiol 1998; $36: 273-4$.

4. Petinaki E., Kontos F., Miriagou V., et al. The bacterial resistance group 2001. Survey of methicillin-resistant coagulase-negative staphylococci in the hospitals of central Greece. Int J Antimicrob Agents 2001;18:563-6.

5. Kloos W.E., Bannerman T.L. Update on clinical significance of coagulase-negative staphylococci. Clin Microbiol Rev 1994; 7:117-40.

6. Sader H.S., Sampaio J.L.M., Zocolli C., Jones R.N. Results of the 1997 SENTRY antimicrobial surveillance program in three Brazilian medical centers. Braz J Infect Dis 1999;3:63-79.

7. Yamazumi T.I.F., Diekema D.J., Pfaller M.A., Jones R.N. Comparison of the Vitek Gram-Positive Susceptibility 106 Card, the MRSA-Screen Latex Agglutination Test, and mecA Analysis for Detecting Oxacillin Resistance in a Geographically Diverse Collection of Clinical Isolates of Coagulase-Negative Staphylococci. J Clin Microbiol 2001;39:3633-6.

8. Facklam R.R., Sahm D., Teixeira L.M. Enterococcus, p.297-305. In PR Murray, EJ Baron, JH Jorgensen, MA Pfaller, RH Yolken (eds), Manual of Clinical Microbiology, American Society of Microbiology, Washington, D.C., 1999.

9. Jett B., Free L., Sahm D.F. Factors influencing the Vitek Gram-positive susceptibility system's detection vanB encoded vancomycinresistance among enterococci. J Clin Microbiol 1996;34:701-6.

10. d’Azevedo P.A., Dias C.A.G., Gonçalves A.L.S., et al. Evaluation of an automated system for the identication and antimicrobial susceptibility testing of enterococci. Diag Microbiol Infect Dis 2001;40:157-61.

11. Martinez F., Chandler L.J., Reisner B.S., Woods G.L. Evaluation of the Vitek card and VTK-RO7.01 software for detection of oxacillin resistance in clinically relevant coagulase-negative Staphylococci. J Clin Microb 2001;39:3733-5.
12. d'Azevedo P.A., Cantarelli V., Inamine E., et al. Avaliação de um sistema automatizado na identificação de espécies de Enterococcus. J Bras Patol Med Lab 2004;40:237-9.

13. Caierão J., Superti S., Dias C.A.G., d'Azevedo P.A. Automated systems in the identification and determination of methicillin resistance among coagulase negative staphylococci. Mem Inst Oswaldo Cruz 2006;101:277-9.

14. Bannerman T.L. Staphylococcus, Micrococcus, and other catalasepositive cocci that grow aerobically, p. 384-404. In: PR Murray, EJ Baron, JH Jorgensen, MA Pfaller, RH Yolken (eds), Manual of Clinical Microbiology, American Society of Microbiology, Washington, D.C., 2003.

15. Merquior V.L.C., Peralta J.M., Facklam R.R., Teixeira L.M. Analysis of electrophoretic whole-cell protein profiles as a tool for characterization of Enterococcus species. Curr Microbiol 1994;28:149-53.

16. Poyart C., Quesne G., Boumaila C., Trieu-Cuot P. Rapid and Accute Species-Level identification of Coagulase-Negative Staphylococci by using the sodA Gene as a Target. J Clin Microbiol 2001;39:4296-301.

17. CLSI - Clinical and Laboratory Standards Institute. Performance standards for antimicrobial susceptibility testing - Fifteenth informational supplement. document M100-S18. Clinical and Laboratory Standards Institute, Wayne, PA, US, 2008.

18. Clarck N.C., Teixeira L.M., Facklam R.R., Tenover F. Detection and differentiation of vanC-1, vanC-2, and vanC-3 glycopeptide resistance genes in enterococci. J Clin Microbiol 1998;36:2294-7.

19. Vannuffel P., Gigi J., Ezzedine H., et al. Specific detection of methicilin resistant Staphylococcus species by multiplex PCR. J Clin Microbiol 1998;33:2864-7.

20. Nonhoff C., Rottiers S., Struelens M.J. Evaluation on the Vitek 2 system for identification and antimicrobial susceptibility testing of Staphylococcus spp. Clin Microbiol Infect 2005;11:150-3. 